\title{
Responsible Leadership: Pathways to the Future
}

\author{
Nicola M. Pless • Thomas Maak
}

Published online: 29 November 2011

(C) Springer Science+Business Media B.V. 2011

\begin{abstract}
This article maps current thinking in the emerging field of responsible leadership. Various environmental and social forces have triggered interest in both research and practices of responsible leadership. This article outlines the main features of the relevant research, specifies a definition of the concept, and compares this emergent understanding of responsible leadership with related leadership theories. Finally, an overview of different articles in this special issue sketches some pathways for ongoing research.
\end{abstract}

Keywords Responsible leadership - Leadership theories and responsibility $\cdot$ Research perspectives

\section{Why Responsible Leadership?}

The answer to this question is multifold. In the introduction to their article on an "alternative perspective of responsible leadership," Waldman and Galvin (2008) suggest a response related to the deficiencies of existing theory and its influence on leadership practice. Specifically, they propose that responsibility is missing from established leadership descriptors, such as transformational,

\footnotetext{
N. M. Pless

Department of Social Science, ESADE Business School, Ramon Llull University, Av. Torreblanca, 59, 08172 Sant Cugat del Vallès, Barcelona, Spain e-mail: nicola.pless@esade.edu

T. Maak $(\bowtie)$

Department of People Management \& Organization, ESADE Business School, Ramon Llull University, Av. Torreblanca, 59, 08172 Sant Cugat del Vallès, Barcelona, Spain

e-mail: thomas.maak@esade.edu
}

charismatic, authentic, participative, servant, shared, or even spiritual and ethical leadership, "and that it is actually this element that is at the heart of what effective leadership is all about. In a nutshell, to not be responsible is not to be effective as a leader" (Waldman and Galvin 2008, p. 327).

Accordingly, we witness a growing discussion about the appropriateness of current leadership theories to address pertinent leadership challenges. This discussion often cites the role and responsibilities of business leaders in society, frequently in light of social and environmental crises such as the Exxon Valdez spill in Alaska, the Bhopal disaster for Union Carbide, Shell's Brent Spar and Nigerian failures, and Nike's sweatshops, to name but a few. These incidents triggered ongoing debate about corporate-level responsibility; more recent discussions of responsible leadership have been inflamed by business scandals and individual leadership failures at the start of the millennium-most prominently the demise of Enron and Arthur Andersen. Following the fall from grace of the "smartest guys in the room" (...), new laws and regulation arose, such as the Sarbanes-Oxley Act, followed by a critical academic debate about the impact of greed and reckless self-interest in managerial decision-making. The discussion recognized "bad management theories [were] destroying good management practice" (Ghoshal 2005) and cited the need for "managers, not MBAs" (Mintzberg 2004), that is, professionals with higher aims and not just "hired hands" (Khurana 2007). Moreover, a call went out for "Responsible Global Leadership" from the European Foundation of Management Development, leading to the emergence of PRME, an educational offshoot of the UN Global Compact that seeks to incorporate the Compact's ten principles into the curricula of business schools worldwide.

Despite the strong push for reforms, irresponsible leadership was a primary cause of the global economic 
crisis of 2008; thus, it became clear that solving leadership issues was a long-term endeavor and that responsible (global) leadership needed to be approached on both individual and systemic levels to be effective. As Jeffrey Sachs (2011, p. 3) argues in a recent book, "A society of markets, laws, and elections is not enough if the rich and powerful fail to behave with respect, honesty, and compassion toward the rest of society and toward the world.... Without restoring an ethos of social responsibility, there can be no meaningful and sustained economic recovery."

The quest for responsible leadership is not limited to scandals and subsequent calls for responsible and ethical conduct though (Brown and Treviño 2006). It also stems from the changes in and new demands of business contexts (e.g., Maak and Pless 2006a; Waldman and Galvin 2008). One such demand is stakeholders' expectation that businesses and their leaders take active roles in fostering responsible behavior, within and outside the organization, such as by creating responsible organizational cultures, pursuing a triple bottom-line (social, environmental, and economic value) approach, and acting as good citizens (Maak 2007; Pless 2007).

As a widening array of stakeholders pay increasing attention to the political role and responsibility of business leaders in the pursuit of a global common good, they ask probing questions about business' role in the fight against poverty and the pursuit of human rights, whether in connection to human rights abuses or as potential enablers of human rights, namely, as secondary agents of justice (Young 2006; Maak 2009). What about business leaders' role in the establishment of intergenerational justice (Wade-Benzoni et al. 2010), such that they serve as stewards of trust that has been embedded in them (Maak and Pless 2006a)? For all parties involved, these are difficult questions to answer. Yet a common understanding in both academic and practitioner discourses indicates that business leaders must be able to answer them if they are to contribute to a sustainable future.

All things considered then, responsible leadership is a multilevel response to deficiencies in existing leadership frameworks and theories; to high-profile scandals on individual, organizational, and systemic levels; and to new and emerging social, ethical, and environmental challenges in an increasingly connected world. The scope and complexity of these challenges calls for responsible leadership and responsible leaders who acknowledge their shared, significant responsibility (May 1996) in tackling problems and challenges. That is, they must walk their talk ultimately to rebuild the public trust vested in them.

It should come as no surprise then that business practice has a notable interest in developing responsible leadership in organizations and in encouraging new generations of responsible leaders and academics to understand the origins and outcomes of responsible leadership as a multilevel theory and construct. In what follows, this opening article of the Special Issue seeks to sharpen understanding of responsible leadership by distinguishing this concept from other leadership theories. We specify our understanding of responsible leadership at the individual level, provide an overview of the various articles in this special issue, and offer some tentative pathways for further research.

\section{What is Responsible Leadership?}

A common understanding among researchers in the field indicates that responsible leadership responds to both existing gaps in leadership theory and the practical challenges facing leadership. First, it centers attention firmly on matters of responsibility, including accountability, appropriate moral decision-making, and trust. In other words, responsible leadership seeks to define what "responsible" means in the context of leadership. Second, being accountable for actions, answerable for decisions, and reliable and trusted are not just semantic variations on the term "responsibility" but rather constitute inherently relational concepts. By definition then, responsible leadership is geared toward the concerns of others and asks for what and to whom leaders are responsible. This comment may seem to be stating the obvious, but it is arguably one of the most under researched concepts in this field, as well as one of the most relevant. At its core, this discussion seeks to clarify who the "others" are and what responding to their concerns entails.

Maak and Pless (2006a, p. 103), in one of the first journal publications on this topic, define responsible leadership as "a relational and ethical phenomenon, which occurs in social processes of interaction with those who affect or are affected by leadership and have a stake in the purpose and vision of the leadership relationship," thereby broadening the view from a traditional leader-subordinate relationship to leader-stakeholder relationships. They shift the focus to the responsibilities that leaders have in relation to various stakeholder groups and accordingly contend that relationships "are the centre of leadership" (Maak and Pless 2006b, p. 39), such that "building and cultivating ... ethically sound relations toward different stakeholders is an important responsibility of leaders in an interconnected stakeholder society" (Maak and Pless 2006a, p. 101). In this case, "others" are all those with a stake in the leadership project.

The level of regard for others and thus stakeholder inclusion varies with the nature of the leadership project. In contrast, the scope of responsibility depends most significantly on how leaders think about their responsibilities 
toward others, because "responsible leadership is not the same concept in the minds of all" (Waldman and Galvin 2008, p. 328). Accordingly we identify two important avenues for research that connect to the very meaning of responsible leadership: one that seeks to investigate conceptually and empirically what might be described as responsible leader mindsets, and another that attempts to clarify who should be included as a relevant other in networks of leader-stakeholder relationships. Research in the former stream can reveal the complexity of responsible leadership, its quality, and underlying sense-making processes; the latter can connect stakeholder theory in general (Freeman et al. 2010) and stakeholder legitimacy in particular (e.g., Mitchell et al. 1997) to leadership theory. Waldman and Galvin's (2008) differentiation of economic versus stakeholder perspectives of responsible leadership suggests a spectrum of mindsets, ranging from low to high levels of regard for others, depending on how individualized or socialized the concept of leadership is. It is worth noting that this spectrum may not range from "lesser" to "more" responsibility; rather, the quality of responsibility and thus responses to stakeholder concerns likely depends as much on contextual and institutional factors as on individual and organizational aspects and thus ultimately determines the appropriate response to any particular situation.

Responsible leadership is not a preconceived construct or predefined remedy to leadership failure and corporate ills. What we see emerging instead is a multilevel theory that connects individual, organizational, and institutional factors (Quigley et al. 2005). In this sense, researchers under the responsible leadership umbrella may deal with individual factors, such as values, virtues, and ethical decision-making; just as they can address organizationallevel leadership, including the links among corporate social responsibility, stakeholder theory, and leadership; and still consider institutional factors and their influence on responsible leadership, such as the societal or cultural context, as defined by factors such as power distance, collectivism, and humane orientation that indicate the extent to which social concerns are part of cultural practices. In both single- and multi-level research, the tentative answer to the question "What is responsible leadership?" must be "It depends." Thus, the field is fluid. It also is reflective of the multiplicity of challenges, questions, and issues at stake in the domain of responsible leadership as illustrated by two extant texts. Doh and Stumpf's (2005) book focuses predominantly on the link between responsible leadership and governance and thus the steering function of responsible leadership with respect to certain issues, industries, and the global common good. The authors in Maak and Pless's (2006b) text are mainly concerned with the conceptual foundations of responsible leadership and seek to contribute to a better understanding of the foundations of responsible leadership. "What is responsible leadership?" "What makes a responsible leader?," and "How can responsible leadership be developed?" are the guiding questions in the latter.

Whereas the previous volumes broke new ground at the conceptual forefront of responsible leadership, we now find a growing number of empirical and descriptive contributions that investigate phenomena at both individual and organizational levels, identifying antecedents and outcomes, examining relationships, and making predictions. This mix of perspectives is accordingly represented in this Special Issue. It zooms in on the current state of research and sets the stage for further research. In particular, five contributions in this issue (by Cameron Freeman, Auster, Voegtlin, Waldman, and Groves) place a specific focus on the individual level of the leader, while three articles (by Gond et al., Pretorius et al., Doh et al.) examine the key phenomena at the organizational level. All these authors emphasize responsible leadership as a relational, valuescentered concept that aims to generate positive outcomes for followers as stakeholders, as specified further next.

\section{How Does Responsible Leadership Differ from Related Theories?}

\section{We understand responsible leadership as a}

values-based and thorough ethical principles-driven relationship between leaders and stakeholders who are connected through a sheared sense of meaning and purpose through which they raise one another to higher levels of motivation and commitment for achieving sustainable values creation and social change (Pless 2007, p. 438).

Concomitantly, we define a responsible leader as a person who reconciles "the idea of effectiveness with the idea of corporate responsibility by being an active citizen and promoting active citizenship inside and outside the organization" (Pless 2007, p. 450). Responsible leaders thus build and cultivate "sustainable relationships with stakeholders ... to achieve mutually shared objectives based on a vision of business as a force of good for the many, and not just a few (shareholders, managers)" (Maak 2007, p. 331). As such, responsible leadership is an inherently normative approach to leadership.

To explore this concept, we turn to the broader domain of other leadership theories and constructs that are relevant to responsible leadership, and specifically those that are values-centered, such as ethical, authentic, servant, and transformational theories of leadership. Through such a comparison, we can provide snapshots, insights, and 
orientations that help us navigate an increasingly diverse field, rather than providing a single-focused, in-depth discussion that would be beyond the scope of this article.

\section{Stakeholder Theory and Responsible Leadership}

With the exception of Schneider (2002), to the best of our knowledge, no one has tried to develop a theory of stakeholder leadership, notwithstanding Bass and Steidlmeier's (1999, p. 200) suggestion to discuss "leadership in the context of contemporary stakeholder theory." We assert that responsible and stakeholder leadership is not just inextricably linked but that responsible leadership provides a convincing perspective on how to connect leadership to stakeholder theory. By making leader-stakeholder relationships the center of attention, responsible leadership focuses on the responsibilities that leaders have in relation to different stakeholder groups. As we have argued elsewhere, "building and cultivating ethically sound relations toward different stakeholders is an important responsibility of leaders in an interconnected stakeholder society" (Maak and Pless 2006a, p. 101). In this view, followers become stakeholders of the leadership project, so responsible leadership must ask a core question: "What is the role of leadership - and of leaders-in a network of stakeholders, and how can a leader lead responsibly across various, potentially conflicting needs and interests?"

Schneider (2002), without explicit reference to matters of responsibility, makes an important contribution by stressing that both the context of organizations and the profound changes in these organizations, as they become flatter, less bureaucratic, and more dispersed, increase the complexity of the leadership project and create new implications for what effective leadership means. Schneider highlights the "radix organization," which has a core but otherwise is flexible (and flat) enough "to meet the challenges of fluctuating vertical, lateral, and external demands" (Schneider 2002, p. 209). She also proposes a stakeholder model of organizational leadership and stresses the importance of context, relationships, leader role-sets, and, to a lesser extent, leader attributes. These components have significant roles with regard to conceptualizations of responsible leadership. Yet, while Schneider's interest refers to the connection of stakeholder leadership and effectiveness, responsible leadership broadens the scope of performance to include responsibility, accountability, legitimacy, and trust.

Ethical Leadership

Ethical leadership represents an individual-level phenomenon (Brown and Treviño 2006; Treviño et al. 2003, 2000), defined as "the demonstration of normatively appropriate conduct through personal actions and interpersonal relationships, and the promotion of such conduct to followers through two-way communication, reinforcement, and decision-making" (Brown et al. 2005, p. 120). The purpose of ethical leadership is to influence followers, generally understood as subordinates in the organization, by demonstrating ethical conduct, often through transactional mechanisms.

With this theory, responsible leadership shares the idea of the leader as a positive role model who behaves virtuously, acts according to ethical standards, insures ethical and pro-social conduct in the workplace, and uses principles of moral reasoning to make decisions (Treviño et al. 2000, 2003). Yet even as achieving, managing, and safeguarding high ethical standards in the workforce are cited as important aspects, they are not sufficient conditions for responsible leadership. Responsible leadership goes beyond ethical perspectives, primarily from a relational point of view. That is, the former stresses the importance of a full-range view of leader-stakeholder relationships, whereas ethical leadership restricts its view to a classical leadership dyad of leader-subordinate. Furthermore, ethical leadership seeks to predict outcomes, such as leader effectiveness, employee job satisfaction, and dedication; responsible leadership transcends this micro-level perspective to focus on multilevel outcomes. In its aspiration to mobilize followers inside and outside the organization to engage in responsible leadership practices, such as contributing to social change and sustainable futures, responsible leadership also encompasses a strong transformational dimension, together with "vision" as an important leadership element. Neither of these elements is part of the ethical leadership construct (Brown and Treviño 2006). Finally, whereas ethical leadership theory considers intraorganizational contextual factors, such as an ethical culture (Treviño 1990), responsible leadership goes further and addresses factors from the cultural context, such as power distance and humane orientation (Pless and Maak 2008).

In summary, the main conceptual differences between ethical and responsible leadership stem from their different paradigmatic outlooks: Ethical leadership is concerned with guidance by leaders in organizations and how leaders can exploit such guidance to improve their effectiveness; responsible leadership recognizes effectiveness as an outcome but mainly seeks to capture the relational nature of the leader-stakeholder project and its implications for matters of responsibility. In turn, it acknowledges the latent tension between ethics and effectiveness and is cautious about exploiting ethics as a tool to enhance leader effectiveness.

\section{Servant Leadership}

The idea of servant leadership, in its current form, was largely developed by Robert K. Greenleaf (1977), a former 
AT\&T executive, after he read Hermann Hesse's novel The Journey to the East, a story of a group of travelers in search of enlightenment that discovers, only after breaking apart, that a servant Leo led the group and held it together. Servant leadership, another individual-level phenomenon, centers primarily on those whom the leader serves, or the followers. Do those served grow as persons? If the answer is yes, the leader was successful and effective. Accordingly, servant leadership is other-directed, rather than oriented toward the leader's self (Stone et al. 2004). It stands in stark contrast with many recent self-serving, real-life leadership episodes, in which leaders first and foremost thought about themselves and their interests rather than about their constituencies. Servant leadership is contradictory with this traditional top-down, individualized, selfcentered form of leadership.

Responsible leadership and servant leadership share the idea that leadership must be mainly about the leader's constituencies (followers or stakeholders), such that the leader's task is to serve the needs and legitimate interests of others (Greenleaf 2002). A leader should anticipate a desirable future, demonstrate genuine care and concern for others, and bring together service and meaning (Sendjaya et al. 2008). Moreover, leaders and followers should "raise one another to higher levels of motivation and morality" (Burns 1978, p. 20) or commitment, in the pursuit of mutually desirable goals. Both versions seek positive outcomes and are normative in nature.

However, though responsible leadership shares with servant leadership the idea of service beyond self-interest, the responsible leader does not pursue "self-sacrificial servanthood" (Sendjaya et al. 2008, p. 405), just for the sake of serving followers and developing their own good. Service is linked to the organizational purpose and directed toward fulfilling the needs of stakeholders throughout business and society. Therefore, the concern of the responsible leader is to mobilize others to serve, engage in, and support objectives tied to a mutually desirable social purpose. That purpose is not limited to helping others grow or become leaders in their own right; it also entails organizational and societal levels (including positive outcomes such as sustainable value creation and social change). The central motivation therefore is not serving others but rather responding to others' interests and needs, including those of outside stakeholders and society at large.

Furthermore, responsible leadership theory understands followers as stakeholders, both inside and outside the organization, not just as followers in the workplace. The development and mobilization of followers inside and outside the organization (individual-level outcomes) is the means by which leadership serves a higher purpose and achieves social change. Although intrinsically motivated, responsible leaders are not necessarily driven by spirituality or an inner calling. Responsible leadership can reflect spiritual, humanistic, moral, or any other values rooted in religion, family, tradition, education, and so on. Or it can stem simply from the recognition that acting with responsibility is the right thing to do. The key difference with servant leadership thus pertains to the level of motivation and contextual factors, which generally get neglected in servant leadership literature.

\section{Authentic Leadership}

Authentic leadership described by proponents in the field as "perhaps the oldest, oldest, oldest wine in the traditional leadership bottle" (Avolio et al. 2005, p. xxii), continues to draw research interest. Early research focused more on inauthentic leadership, that is, on the lack of authenticity. But current research is more concerned with positive outcomes and the role of authenticity-which in the most generic terms refers to being one's true self or being true to who you are-in the spirit of positive organizational scholarship (Cameron et al. 2003). Luthans and Avolio (2003, p. 243) thereby define authentic leadership as "a process that draws from both positive psychological capacities and a highly developed organizational context." Despite being a multilevel construct (including components from organizational, group, and individual levels), it centers mostly on processes at the individual level. Selfawareness (i.e., a deep sense of self that provides knowledge about one's values, identity, emotions, and motives/ goals), self-regulatory processes that align values with intentions and actions, and positive psychological states all represent important mechanisms that enable authentic leaders to influence, energize, and develop followers. In this case, followers are subordinates, but a core assumption of authentic leadership theory is that it will lead to trust, engagement, and well-being and thus to leadership effectiveness. Contextual factors such as uncertainty, culture/ climate, and inclusion are considered, to the extent that they moderate the outcomes of authentic leadership.

Ethical qualities, such as moral capacity, courage, and transparency are understood as positive psychological resources. Although some authors (Avolio and Gardner 2005, Luthans and Avolio 2003, May et al. 2003) understand ethics as an inherent component of authentic leadership, others (Cooper et al. 2005, Shamir and Eilam 2005, Sparrowe 2005) voice concerns about defining authentic leadership as encompassing moral resources.

Responsible leadership appears to overlap with authentic leadership with respect to its self-awareness and selfregulation components (Pless and Maak 2005), but it also goes further. Pless and Maak (2005) specify that responsible leadership requires leaders to take another step to develop a sense of others' emotions and values/norms, 
reflect on the adequacy of their own emotions and values, and assess them in comparison with general standards and hypernorms (Donaldson and Dunfee 1999), as well as with local needs. Moreover, ethical qualities constitute a structural element in responsible leadership research; in that sense, they are more than positive psychological resources. Moral awareness, ethical reflection, an ability to employ moral imagination to reconcile dilemmas (Werhane 1999), and moral deliberation and decision-making skills are all important features of responsible leadership.

Both authentic and responsible leadership theories factor in the organizational impact of leadership. Avolio and Gardner (2005), Avolio et al. (2004), and Luthans and Avolio (2003) assert that authentic leadership can have positive organizational impacts by helping people find meaning at work and contributes to sustained performance and growth through long-term value creation for shareholders (Avolio and Gardner 2005). Similar to authentic leadership, responsible leadership aims for positive organizational outcomes, but extending beyond traditional economic outcome variables, it also proposes that leadership includes contributions to value and social capital by stakeholders in business and society and thus ultimately should result in positive social change (Maak 2007; Pless 2007).

\section{Transformational Leadership}

Leadership is always about change, whether on the individual, team, organizational, or societal levels, or a combination thereof. Leaders, whether by appointment, dedication, or accident, influence followers (stakeholders), and vice versa, which leads to the realization of certain objectives. Reaching the objective implies a change process-thus, transformation.

The notion of transformational leadership was introduced by Burns (1978) in the context of political leadership, then further developed and conceptualized by Bass (1985) and his colleagues (e.g., Bass and Avolio 1995; Avolio et al. 1991). As an individual-level phenomenon, transformational leadership entails a process of building commitment and empowerment among followers to accomplish organizational goals (Stone et al. 2004; Yukl 2002) and thus enhance follower performance. Research on transformational leadership considers some contextual factors, such as country culture or organizational culture, but it does not explicitly discuss "leadership in the context of contemporary stakeholder theory" (Bass and Steidlmeier 1999 , p. 200), which instead is the specific contribution of responsible leadership theory.

Responsible leadership is close to the transformational notions of vision, inspiration, intellectual stimulation, and individualized consideration. But it also differs in several aspects. First, in terms of the definition of followers, responsible leadership considers them more broadly as stakeholders inside and outside the organization.

Second, with regard to the emphasis of leadership, transformational leaders influence followers for the instrumental purpose of enhancing performance and accomplishing organizational objectives (e.g., improving the economic bottom-line, satisfying shareholders), at least in the prevailing approach proposed by Bass and colleagues. Responsible leaders instead serve different stakeholders and mobilize them to engage in and support objectives tied to a higher social purpose at organizational and societal levels. In this contrast, we find a shift from a shareholder mindset to a stakeholder orientation (Maak and Pless 2006a; Waldman and Galvin 2008).

Third, responsible leadership is less focused on individual characteristics, such as defining the "great man" or the charismatic and transformative leader. Instead, it is geared toward a relational leadership approach (Uhl-Bien 2006) based on inclusion, collaboration, and cooperation with different stakeholder groups. Maak and Pless (2006a) point out that in the broader leadership context of stakeholder interaction, leadership entails new responsibilities and roles, and the leader becomes a coordinator and cultivator of relationships with different constituencies-a weaver in and among a network of relationships (Maak 2007).

Fourth, research on transformational leadership asserts that the leader's ethical or unethical behavior depends on his or her motivation: Only authentic, transformational leaders qualify as moral leaders with moral values, social motivations, and a lack of coercion or manipulative influence (Bass 1985, Brown and Treviño 2006). In other words, there appears to be a distinction between inauthentic and authentic transformational leaders. In contrast, responsible leadership constitutes an inherently ethical phenomenon: To qualify as responsible, leaders must be considered responsible and thus accountable, trustworthy, and ethical. A responsible leader is a person of character with ethical literacy (moral reasoning, moral imagination), who makes moral and principled decisions by considering their impacts on others, while also using his or her influence and power to pursue moral and legitimate ends through justifiable means.

Fifth, both transformational and responsible leadership include notions of change and transformation. However, responsible leaders employ change as a means to achieve a higher social goal; transformational leaders do not necessarily follow that path.

As this overview has demonstrated, previous leadership approaches understand it as an individual-level phenomenon and examine the characteristics, styles, and/or processes that mark that individual, as the basic unit of 
analysis. Researchers also assume some shared conceptual leadership characteristics: Apart from a general valuescentered philosophy, they regard role modeling as an important part of positive leadership, stress the intrinsic motivation for leadership, and focus on caring concern for others or a high level of other-regard (e.g., Brown and Treviño 2006). To varying degrees, they also understand ethics as an inherent component of leadership. However, with the exception of responsible leadership, none of these approaches includes the social and natural environment as a pertinent level of analysis, links leadership to the outcomes of sustainable value creation or social change (i.e., for the benefit of all legitimate stakeholders), or defines followers in a broad sense as stakeholders within and outside the organization. Maak and Pless (2006a, b) stress that leadership in a network of stakeholder relationships not only induces new roles and responsibilities but also creates a new social perception of leadership, in which the leader is a coordinator and a cultivator of relationships with different constituencies, across and beyond the organization. That is, we need to rethink leadership as leadership of a network of stakeholder relationships.

\section{Perspectives on Responsible Leadership: Special Issue Overview}

Of the eight contributions in this Special Issue, three articles are conceptual and five are empirical. More and more researchers adopting an empirical-descriptive approach investigate responsible leadership at both individual and organizational levels, identify antecedents and outcomes, examine relationships, and make predictions. All authors emphasize responsible leadership as a relational and values-centered phenomenon that aims at generating positive outcomes for followers as stakeholders.

Values, Authenticity, and Responsible Leadership

In "Values, Authenticity, and Responsible Leadership," Ed Freeman and Ellen Auster rethink the concept of authenticity according to its application in modern organizational life, such that they enrich extant theory on responsible leadership. The authors reflect on some foundational questions about the logic of values, arguing that the idea of simply "acting on one's values" or "being true to oneself" - what has been called the "essentialist self"- at best establishes a starting point for thinking about authenticity, because of the difficulty of knowing one's own values and acting accordingly. They propose the idea of the "poetic self," a creative project by which the leader seeks to live authentically. Trying to be authentic is an ongoing process that starts with engaging perceived values while also analyzing one's own history (self-enlargement), relationships with others (self-connection), and aspirations for the future. This process of self-creation demands a mutual connection with community and stakeholders. Even organizations can become poetic if they comprehend the processes of self-understanding, connection, and aspiration (i.e., perceived organizational values, analysis of historical routines, awareness of the network of stakeholder relationships, and consciousness of a purpose or aspiration). Because authenticity requires acting on perceived values, it provides a starting point for ethics as well. The idea of responsible leadership thus expands with this new conceptualization of the self and authenticity, such that it may help create more humane organizations.

\section{Responsible Leadership as Virtuous Leadership}

Kim Cameron, in "Responsible Leadership as Virtuous Leadership," equates responsible leadership with accountability, dependability, authority, and empowerment—but above all with virtuousness. Using this connotation entails three assumptions about responsible leadership: (1) eudaemonism, or the assumption that all people are inclined toward moral goodness; (2) inherent value, such that virtuousness represents a "good of first intent"; and (3) amplification, which is the assumption that observing virtuousness creates a self-reinforcing cycle of more virtuousness. In turn, it leads to two important outcomes. Virtue establishes a fixed point for coping with change, because it helps identify the universally accepted standard for what leaders may consider best for other individuals and their organizations. It also offers benefits for constituents who otherwise would never have been affected. By focusing on virtuous outcomes, the leader can achieve desirable ends, such as organizational commitment or performance, that insure advantages for all constituencies-rather than benefiting some at the expense of others.

\section{Responsible Leadership Outcomes Via Stakeholder CSR Values}

In his study "Responsible Leadership Outcomes Via Stakeholder CSR Values: Testing a Values-Centered Model of Transformational Leadership," Kevin Groves proposes a conceptual link between responsible and transformational leadership theories and examines how transformational leadership advances responsible leadership outcomes through leader values, leadership behavior, and follower perceptions of leader-follower values congruence. The responsible leadership outcomes include followers' beliefs in a stakeholder CSR perspective and willingness to engage in citizenship behaviors that benefit both the organization and wider society. The author tests 
his values-centered leadership model, comprising leader stakeholder and economic values, follower values congruence, and responsible leadership outcomes, with data from 122 organizational leaders and 458 direct reports. A structural equation modeling analysis demonstrates that leader stakeholder values predict transformational leadership; leader economic values are more associated with transactional leadership. Follower values congruence also appears strongly associated with transformational leadership but unrelated to transactional leadership; it partially mediates the relationships of transformational leadership with both follower organizational citizenship behaviors and follower beliefs in the stakeholder view of CSR. By adhering to stakeholder values and creating strong follower perceptions of shared values, transformational leaders can influence followers' beliefs in the stakeholder CSR perspective and willingness to engage in extra-role, citizenship behaviors that address organizational and community problems.

\section{Measuring Responsible Leadership}

Christian Voegtlin's article, "Development of a Scale Measuring Responsible Leadership," extends understanding of responsible leadership with an ideal of discourse ethics that enables leaders to act morally and engage in dialogue with all affected constituents, which grants the organization a license to operate. This understanding of responsible leadership might address the challenges of globalization better than existing leadership concepts. The proposed empirical scale of responsible leadership enables descriptive and prescriptive evaluations; it validates a one-dimensional construct with high internal consistency, as well as discriminant and predictive validity. Thus, responsible leadership reflects the pertinent hierarchical level; can reduce unethical behavior among a primary stakeholder group, namely, employees; and has a direct impact on the job satisfaction of direct report employees. This effect of responsible leadership on job satisfaction also is partly mediated by observed unethical behavior. In this sense, responsible leaders have an indirect effect on job satisfaction, because they help create a more ethical work environment.

Moving Forward with the Concept of Responsible Leadership

The aim of David Waldman's article "Moving Forward with the Concept of Responsible Leadership: Three Caveats to Guide Theory and Research" is to point out three issues that must be considered if we are to progress in the area of responsible leadership. The first caveat pertains to definitional issues: Multiple definitions and moral bases exist to conceptualize responsible leadership, all of might be equally legitimate and valid (e.g., shareholder view, normative stakeholder theory). The second point to the importance of recognizing the strong values and potential ideologies of the researcher. To advance the concept of responsible leadership, it is crucial that theory and research are not ideologically driven or biased. The third caveat is connected to the positioning of responsible leadership within the body of leadership theory and research according to its "otherregarding focus" (i.e., leaders' accountability to various stakeholders). Thus, responsible leadership offers unique, beneficial, new, or complementary insights. This author also notes concerns about the measurement of responsible leadership. Useful measures should integrate multiple perspectives on leader's values and behaviors, from different types of stakeholders rather than just from immediate followers. Finally, he notes the importance of further descriptive research in the domain of responsible leadership.

\section{Responsible Leadership Helps Retain Talent}

In "Responsible Leadership Helps Retain Talent in India," Jonathan Doh, Stephen Stumpf, and Walter Tymon approach responsible leadership as an organizational-level phenomenon. Drawing on stakeholder theory, they define and operationalize it from the perspective of employees and their views of leaders' actions. With this "inclusive concept ... employees perceive their organization as having an ethical and proactive stakeholder perspective toward constituents outside the organization and the employees themselves." Their empirical study is based on a survey involving 28 organizations operating in India and 4,352 employees; it underscores the critical role of responsible leadership for employee retention. These authors also propose a tripartite employee view of responsible leadership: (1) employees' perception of a strong stakeholder culture that supports acting in a socially responsible and ethical manner, (2) fair and inclusive human resource practices, and (3) positive managerial support for employee development and success. The components of responsible leadership also relate to employees' pride in and satisfaction with the organization, as well as their retention.

Exploring the Interface Between Strategy-Making and Responsible Leadership

In "Exploring the Interface Between Strategy-Making and Responsible Leadership.” Rachel Maritz, Marius Pretorius, and Kato Plant report on the thinking of organizational leaders, managers and non-managers regarding strategymaking modes. Empirical findings, based on mixed method research (analyses of in-depth interviews and 210 questionnaires) conducted in South Africa, reveal that 
organizations combine deliberate strategy-making modes (i.e., formal, rational, comprehensive approach with articulated vision, direction, and specific ends and means) with emergent strategy-making efforts (i.e., quick response, adaptive, trial-and-error with vague ends and means, flexible planning structures, and tolerance for change). These strategy-making modes have key implications for the responsible leader, as an architect or change agent. For example, the high performance consensus (neutral part of strategy-making) in these organizations leads to greater tolerance for risk-taking. Organizational leaders must remain cognizant of the growing use and characteristics of emergent strategy-making, if they hope to facilitate effective governance. Further understanding of these characteristics could provide guidance for leaders who want to be both responsive and responsible in all their actions areas.

\section{The Human Resources Contribution to Responsible Leadership}

The article by Jean-Pascal Gond and colleagues, "The Human Resources Contribution to Responsible Leadership: An Exploration of the CSR-HR Interface," aims to investigate how human resources (HR) contribute to socially responsible leadership at functional, practical, and relational levels of analysis. Although CSR practices have been embraced by many corporations, the authors argue that the specific contributions of HR professionals, HR management practices, and employees to responsible leadership have been overlooked. Relying on analyses of interviews with $30 \mathrm{CSR}$ and HR corporate executives from 22 corporations operating in France, these authors determine whether and how HR can support employees' involvement in CSR, while also highlighting areas of collaboration and tension between HR and CSR functions around emerging practices of responsible leadership. The findings uncover the multiple, often implicit roles of HR in responsible leadership, as well as the interrelation of functional, practical, and relational dimensions. In its organizational and functional contribution, the optimal configuration of the HR-CSR interface enables HR to provide functional support to the deployment of responsible leadership. With regard to a practical contribution, HR professionals help insure stabilized or encourage emerging practices and thus build the environment to support responsible leadership. For the relational contribution of HR, this article notes that HR professionals manage relationships with employees, facilitate employees' involvement and representation in CSR issues and topics, and monitor the CSR influence on employees through HR processes. Finally, the organization of the HR-CSR interface can enable or undermine HR contributions to responsible leadership; several underlying cognitive factors shape this interface.

\section{Conclusion: Pathways for Further Research}

The field of responsible leadership is still in its infancy. Further guidance on the topic remains in high demand, yet most responsible leadership dimensions remain under researched. This situation is not necessarily surprising; most leadership research still assumes that leadership takes place in clearly structured, hierarchical relationships and that researchers can uncover some ultimate truth about what constitutes "effective" leadership. The world of leadership is messier than that-more complex, diverse, and ultimately contested, especially when it comes to defining responsibility. Moreover, the objectivist stance of traditional concepts and the ignorance of normative issues makes it difficult to determine how such research could inform those who look for guidance in matters of responsible leadership.

We hope that this Special Issue not only helps consolidate responsible leadership as an important area of research but also, and perhaps more importantly, inspires additional research that generates orienting knowledge in this domain. The field is far from complete, and the contributions in this issue provide only a snapshot of the challenges and concerns that remain to be studied.

In particular, further research should address definitional issues, as David Waldman notes in his contribution: Multiple definitions and moral bases attempt to conceptualize responsible leadership, all of which might be equally legitimate and valid. Additional explorations of these bases would generate more clarity, which not least might prevent the domain from becoming ideologically driven or biased. Waldman also suggests that responsible leadership should be better positioned within the wider stream of leadership theory and research. Our brief overview might offer a starting point for cross-comparisons of responsible leadership with other leadership concepts. In addition, research could explore team and shared leadership further (Pearce and Conger 2003), link emerging literature on followership or follower-centric approaches to responsible leadership (Shamir and Eilam 2005), and so on.

As research seeks to refine responsible leadership, it would be helpful to have scales and constructs for testing. Christian Voegtlin has provided some indications of how to pursue this avenue. Measures of responsible leadership, though not a primary interest of researchers at this stage, might provide more substantial evidence regarding its relevance and effectiveness. Potential constructs to study might include job satisfaction, implicit leadership theory, and ethical leadership as perceived by immediate followers. By obtaining multiple perspectives on leaders' values and behaviors from different types of stakeholders, rather than just immediate followers, as Waldman suggests, we also could gain important insights into legitimacy, 
stakeholder satisfaction, and leader-stakeholder dynamics. The time also seems ripe to study the role of leadership in building stakeholder social capital (Maak 2007). Research needs to provide more clarity regarding who should be included as a relevant other in the network of leaderstakeholder relationships, which would enable connections from stakeholder theory in general (Freeman et al. 2010) and from stakeholder legitimacy in particular (e.g., Mitchell et al. 1997) to leadership theory.

We also see great benefit in investigating, both conceptually and empirically, responsible leader mindsets. Research in this area could reveal the great complexity of responsible leadership, its quality, and underlying sensemaking processes; it also might shed light on anecdotal evidence that leaders think differently about doing the right thing. Waldman and Galvin's (2008) differentiation of economic versus stakeholder perspectives even hints at the possibility of a spectrum of mindsets. In this sense, we hope that we continue to see more descriptive research on responsible leadership that generates deeper, more insightful understanding of the phenomenon.

\section{References}

Avolio, B. J., \& Gardner, W. L. (2005). Authentic leadership development: Getting to the root of positive forms of leadership. The Leadership Quarterly, 16, 315-338.

Avolio, B. J., Gardner, W. L., \& Walumbwa, F. O. (Eds.). (2005). Preface, in their Authentic leadership theory and practice: Origins, effects and development. Bingley: Emerald.

Avolio, B. J., Gardner, W. L., Walumbwa, F. O., Luthans, F., \& May, D. R. (2004). Unlocking the mask: A look at the process by which authentic leaders impact follower attitudes and behaviors. The Leadership Quarterly, 15, 801-823.

Avolio, B., Waldman, D., \& Yammarino, F. (1991). Leading in the 1990's: The four l's of transformational leadership. Journal of European Industrial Training, 15, 9-16.

Bass, B. M. (1985). Leadership and performance beyond expectations. New York, NY: The Free Press.

Bass, B. M., \& Avolio, B. J. (1995). MLQ multifactor leadership questionnaire for research. Palo Alto, CA: Mind Garden.

Bass, B. M., \& Steidlmeier, P. (1999). Ethics, character, and authentic transformational leadership behavior. The Leadership Quarterly, $10(2), 181-217$

Brown, M. E., \& Treviño, L. K. (2006). Ethical leadership: A review and future directions. The Leadership Quarterly, 17, 595-616.

Brown, M. E., Treviño, L. K., \& Harrison, D. (2005). Ethical leadership: A social learning perspective for construct development and testing. Organizational Behavior and Human Decision Processes, 97, 117-134.

Burns, J. M. (1978). Leadership. New York, NY: Harper and Row.

Cameron, K., Dutton, J., \& Quinn, R. E. (Eds.). (2003). Positive organizational scholarship. San Francisco: Berrett-Koehler.

Cooper, C., Scandura, T. A., \& Schriesheim, C. A. (2005). Looking forward but learning from our past: Potential challenges to developing authentic leadership theory and authentic leaders. The Leadership Quarterly, 16, 475-493.
Doh, J., \& Stumpf, S. (Eds.). (2005). Handbook of responsible leadership and governance in global business. London: Edward Elgar.

Donaldson, T., \& Dunfee, T. W. (1999). The promise and peril of global business ethics. California Management Review, 41, $45-63$.

Freeman, R. E., Harrison, J. S., Wicks, A. C., Parmar, B. L., \& De Colle, S. (2010). Stakeholder theory, the state of the art. Cambridge: University Press.

Ghoshal, S. (2005). Bad management theories are destroying good management practices. Academy of Management Learning \& Education, 4, 75-91.

Greenleaf, R. K. (2002). Servant leadership: A journey into the nature of legitimate power and greatness, 25th Anniversary ed. New York, Mahwah, NJ: Paulist Press.

Khurana, R. (2007). From higher aims to hired hands: The social transformation of American business schools and the unfulfilled promise of management as a profession. Princeton: Princeton University Press.

Luthans, F., \& Avolio, B. J. (2003). Authentic leadership: A positive developmental approach. In K. S. Cameron, J. E. Dutton, \& R. E. Quinn (Eds.), Positive organizational scholarship (pp. 241-261). San Francisco: Berrett-Koehler.

Maak, T. (2007). Responsible leadership, stakeholder engagement and the emergence of social capital. Journal of Business Ethics, 74(4), 329-343.

Maak, T. (2009). The cosmopolitical corporation. Journal of Business Ethics, 84, 361-372.

Maak, T., \& Pless, N. M. (2006a). Responsible leadership in a stakeholder society-A relational perspective. Journal of Business Ethics, 66, 99-115.

Maak, T., \& Pless, N. M. (2006b). Responsible leadership. London/ New York: Routledge.

May, L. (1996). Sharing responsibility. Chicago: University of Chicago Press.

May, D. R., Chan, A. Y. L., Hodges, T. D., \& Avolio, B. J. (2003). Developing the moral component of authentic leadership. Organizational Dynamics, 32, 247-260.

Mintzberg, H. (2004). Managers not MBAs: A hard look at the soft practice of management and management development. San Francisco, CA: Berrett-Koehler.

Mitchell, R. K., Agle, B. R., \& Wood, D. J. (1997). Toward a theory of stakeholder identification and salience: Defining the principle of who and what really counts. Academy of Management Review, 22(4), 853-886.

Pearce, C. L. \& Conger, J. A. (Eds.). (2003). Shared leadership: Reframing the hows and whys of leadership. Thousand Oaks/ London/New Delhi: Sage.

Pless, N. M. (2007). Understanding responsible leadership: Roles identity and motivational drivers. Journal of Business Ethics, 74(4), 437-456.

Pless, N. M., \& Maak, T. (2005). Relational intelligence for leading responsibly in a connected world. In K. M. Weaver (Ed.) Best Paper Proceedings of the Sixty-Fifth Annual Meeting of the Academy of Management, Honolulu, HI.

Pless, N. M., \& Maak, T. (2008). Business-in-society competence for leading responsibly in a global environment. INSEAD Faculty \& Research Working Paper, 2008/22/OB. Fontainebleau \& Singapore.

Quigley, N. R., Sully de Luque, M., \& House, R. J. (2005). Responsible leadership and governance in a global context. Insights from the GLOBE study. In J. Doh \& S. A. Stumpf (Eds.), Handbook on responsible leadership and governance in global business. Cheltenham, UK: Edward Elgar.

Sachs, J. (2011). The price of civilization: Economics and ethics after the fall. London: The Bodley Head. 
Schneider, M. (2002). A stakeholder model of organizational leadership. Organization Science, 13(2), 209-220.

Sendjaya, S., Sarros, J. C., \& Santora, J. C. (2008). Defining and measuring servant leadership behaviour in organizations. Journal of Management Studies, 45, 403-424.

Shamir, B., \& Eilam, G. (2005). "What's your story?": A life-stories approach to authentic leadership development. The Leadership Quarterly, 16, 395-417.

Sparrowe, R. T. (2005). Authentic leadership and the narrative self. The Leadership Quarterly, 16, 419-439.

Stone, A. G., Russell, R. F., \& Patterson, K. (2004). Transformational versus servant leadership: A difference in leader focus. Leadership and Organization Development Journal, 25, 349-361.

Treviño, L. K. (1990). A cultural perspective on changing organizational ethics. In R. Woodman \& W. Passmore (Eds.), Research in organizational change and development (pp. 195-230). Greenwich, CT: JAI Press.

Treviño, L. K., Brown, M., \& Hartman, L. P. (2003). A qualitative investigation of perceived executive ethical leadership:
Perceptions from inside and outside the executive suite. Human Relations, 55, 5-37.

Treviño, L. K., Hartman, L. P., \& Brown, M. (2000). Moral person and moral manager: How executives develop a reputation for ethical leadership. California Management Review, 42, 128-142.

Uhl-Bien, M. (2006). Relational leadership theory: Exploring the social processes of leadership and organizing. The Leadership Quarterly, 17(6), 654-676.

Wade-Benzoni, K. A., Sondak, H., \& Galinsky, A. D. (2010). Leaving a legacy: Intergenerational allocations of benefits and burdens. Business Ethics Quarterly, 20(1), 7-34.

Waldman, D. A., \& Galvin, B. M. (2008). Alternative perspectives of responsible leadership. Organizational Dynamics, 37, 327-341.

Werhane, P. H. (1999). Moral imagination and management decision making. New York/Oxford: Oxford University Press.

Young, I. M. (2006). Responsibility and global justice: A social connection model. Social Philosophy \& Policy, 23(1), 102-130.

Yukl, G. (2002). Leadership in organizations (5th ed.). Upper Saddle Creek, NJ: Prentice-Hall. 